\title{
A novel technique for developing bimodal grain size distributions in low carbon steels
}

\author{
H. Azizi-Alizamini, M. Militzer, W. J. Poole \\ The Centre for Metallurgical Process Engineering, The University of British Columbia \\ Vancouver, Canada, V6T 1Z4
}

In this study a new method is introduced to produce bimodal grain structures in low carbon steels. This method is based on cold rolling of dual phase structures and appropriate annealing treatments. The difference in the recrystallization behaviour of ferrite and martensite yields a heterogeneous microstructure with a distribution of coarse and fine grains. These types of microstructures are of interest for optimizing the balance of strength and uniform elongation in ultra-fine grained low carbon steels.

Keywords: Steel, Dual phase, Rolling, Annealing, Bimodal grain distribution

Recently, ultra-fine grained (UFG) low carbon steels have received significant attention to obtain higher strength and ductility and a decrease in ductilebrittle transition temperature (DBTT) [1,2]. A number of thermomechanical approaches have been developed in order to produce UFG structures in low carbon steel $[3,4,5]$. For example, Tsuji et al. [6] have shown that cold rolling and annealing of a fully martensitic 0.13 wt.\% carbon steel can yield an UFG ferrite structure which has a good combination of strength and ductility. However, these steels showed the undesirable presence of extensive Lüders banding which affects the surface finish and the uniform elongation behaviour of these materials [7]. In addition, cold rolling of fully martensitic structures represents a challenge to industry. Other strategies that have been considered to improve strength-ductility combinations include the introduction of second phase particles and/or bimodal size distributions of the grains in the microstructure $[8,9,10]$. For example Wang and $\mathrm{Ma}$ have demonstrated that copper with a bimodal distribution of grains yields a superior combination of yield stress and uniform elongation [11]. Zhao et al. developed bimodal UFG ferrite/cementite microstructure through annealing of warm rolled low carbon steel in ferrite [12]. They utilized heterogeneous distribution of cementite particles localized within the pearlite lamellae which spheroidized during rolling [12]. Further, Hanamura et al. [1] have shown that UFG ferrite/cementite microstructure with bimodal distribution of ferrite grains has a larger impact toughness compared to conventional microstructures, which include ferrite/pearlite, quenched and quenched and tempered martensite, in a low carbon steel.

The present work proposes a new method to create bimodal microstructures in low carbon steels. The hypothesis for the current work was developed from the observations that under suitable conditions, the martensite in ferrite-martensite dual phase steels codeforms with the ferrite [13]. Thus, it was proposed that a bimodal grain size distribution could be produced by cold rolling of a ferrite-martensite dual phase steel and then annealing, i.e. the ferrite would recrystallize resulting in a conventional grain size and the deformed martensite would recrystallize to form UFG ferrite.

The composition of the steel used in this study was $0.17 \mathrm{C}, 0.74 \mathrm{Mn}, 0.04 \mathrm{Al}, 0.008 \mathrm{P}, 0.009 \mathrm{~S}$ and $0.0047 \mathrm{~N}$ (wt.\%). The thermomechanical treatment is schematically summarized in Figure 1. The samples were initially austenitized at $1000^{\circ} \mathrm{C}$ for $30 \mathrm{~min}$ followed by rapid quenching into an ice brine solution (stage I in Fig. 1). The resulting martensite structure was then intercritically annealed in a salt bath at $740^{\circ} \mathrm{C}$ for $10 \mathrm{~min}$ followed by direct quenching into an ice brine solution (stage II). The resulting ferrite/martensite dual phase structure was cold rolled by a $50 \%$ reduction with a laboratory rolling mill (roll diameter: $130 \mathrm{~mm}$ ) (stage III), then annealed between $500-600^{\circ} \mathrm{C}$ for different times in an $\mathrm{Ar}$ atmosphere (step IV) before water quenching. Among different annealing conditions, holding at $525^{\circ} \mathrm{C}$ for $1200 \mathrm{~min}$ was found to offer an appropriate condition for developing a bimodal structure. Except for the second stage, i.e. intercritical annealing, the process is similar to that of martensite straining to produce an UFG structure. Details about the martensite straining process can be found elsewhere [14,15]. Microstructures of the deformed and annealed samples were characterized in the transverse direction of the rolled sheet, i.e. the plane perpendicular to both the rolling direction and the normal direction to the rolling plane. Samples for microstructure examination were electropolished in 95\% acetic acid and 5\% perchloric acid solution and then etched with $3 \%$ nital. The microstructures were examined by scanning electron microscopy (SEM) using the secondary electron 
detector. Grain size measurements were based on the equivalent area diameter (EQAD) approach and at least 1200 grains were analyzed. The deformation of the martensite phase $\left(\varepsilon_{\text {mart. }}^{\text {thick. }}\right)$ was measured through a series of thickness measurements of the martensite islands before and after rolling using Clemex image analyzer software. Details of the procedure for the strain measurement can be found in reference [13]. At least 30 different images from different locations through the thickness were examined amounting to approximately 20,000 measurements in both asquenched and as-rolled samples. Further, to quantify the resulting mechanical properties, tensile tests were conducted on samples with $40 \mathrm{~mm}$ gauge length at a nominal strain rate of $10^{-3} \mathrm{~s}^{-1}$ using a MTS servohydraulic machine.

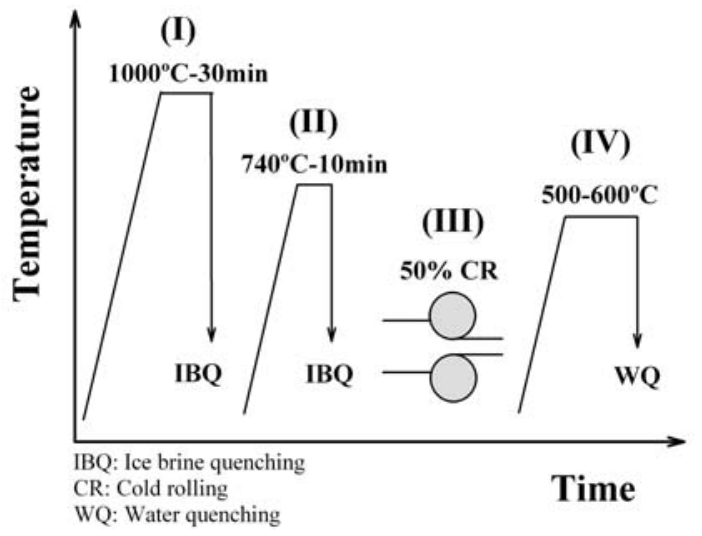

Figure 1: Schematic representation of thermomechanical process.

Figure 2a illustrates the dual phase structure produced by intercritical annealing and quenching; the structure consists of $60 \pm 1 \%$ ferrite and $40 \pm 1 \%$ martensite measured using the Clemex image analysis software. Ferrite grains were primarily equiaxed in morphology and ranged from 2 to $6 \mu \mathrm{m}$ in size. The martensite islands have an irregular shape varying from a lath type to a roughly equiaxed structure. The carbon concentration in austenite after intercritical annealing was estimated to be $0.4 \mathrm{wt}$. \%, using mass balance. Figure $2 \mathrm{~b}$ shows the dual phase structure after $50 \%$ cold reduction (equivalent strain of 0.8 ). Deformation of ferrite matrix with martensite particles results in a heterogeneous distribution of the plastic strain. The ferrite matrix is heavily deformed whereas plastic deformation of martensite occurs to a far lower extent. Measurement of the change in martensite islands' thickness before and after deformation gives a strain level for martensite of $\varepsilon_{\text {mart. }}^{\text {thick. }}=0.10 \pm 0.01$. This strain indicates that there is plastic deformation of martensite albeit at a level considerably below the applied rolling strain. In addition, it can be observed in Fig. $2 b$ that in some cases the thinner martensite laths break into smaller particles (Fig. 2b).

After annealing of the deformed structure at $525^{\circ} \mathrm{C}$ for $1200 \mathrm{~min}$ it can be seen that both the ferrite and martensite recrystallize (Fig. 2c). Further, precipitation of iron carbide $\left(\mathrm{Fe}_{3} \mathrm{C}\right)$ occurs in the martensite regions during the annealing step. As a result, a heterogeneous microstructure forms consisting of areas of fine grains with sizes of $2 \mu \mathrm{m}$ and smaller in a matrix of larger grains with sizes ranging from $3-15 \mu \mathrm{m}$.
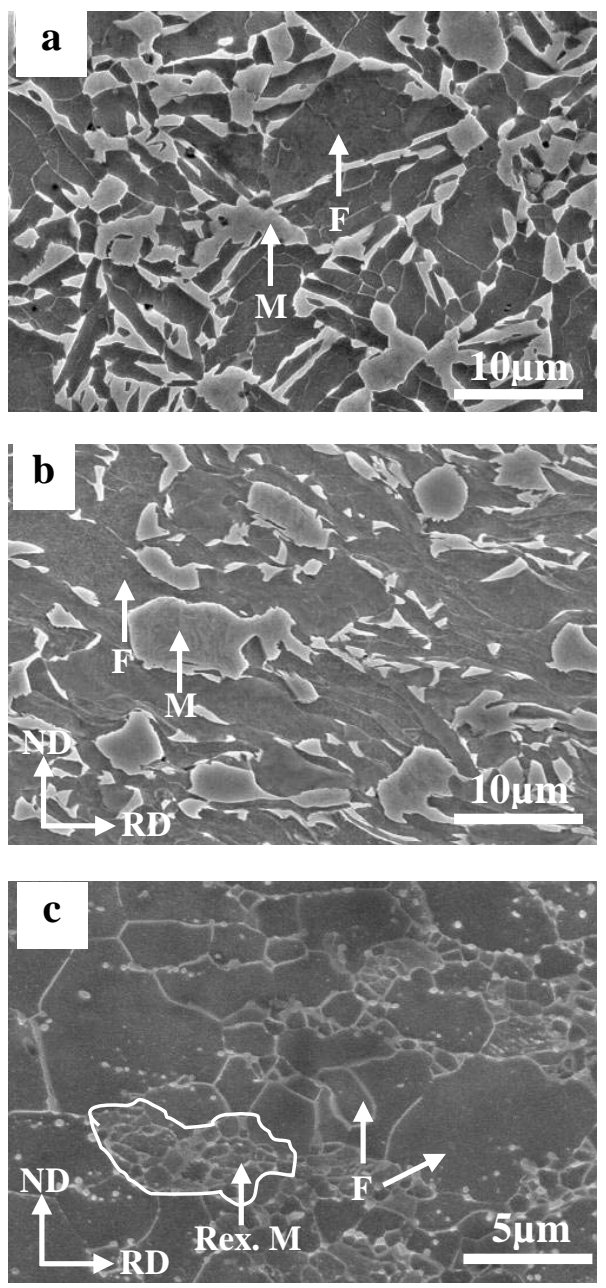

Figure 2: SEM micrograph of (a) initial dual phase microstructure, (b) dual phase microstructure after 50\% cold reduction, (c) final structure after annealing at $525^{\circ} \mathrm{C}$ for $1200 \mathrm{~min}$. "F", "M" and "Rex. M" represent ferrite, martensite and recrystallized martensite, respectively.

The grain size distribution obtained for this heterogeneous microstructure is depicted in Figure 3. Figure 3a shows the measured size distribution of the entire range of grain sizes (bar chart) together with a log-normal fit (solid line curve), i.e. [16]: 


$$
f(x)=\frac{1}{x \sigma \sqrt{2 \pi}} \exp \left(\frac{-\left\{\ln \left(x / x_{p}\right)\right\}^{2}}{2 \sigma^{2}}\right)
$$

where $x$ is the grain diameter, $\sigma$ is the standard deviation of natural logarithm of $x$ and $x_{p}$ is the median grain size. In the present case, a good fit to the distribution is obtained with $\sigma=0.55$ and $x_{p}=0.4 \mu \mathrm{m}$. At first sight, the log-normal fit appears to provide an adequate description of the grain size distribution. However, closer examination indicates that there is a clear tail of large grains which lie outside the lognormal distribution. Because there are many more small grains in the distribution, these grains determine the apparent character of the grain size distribution. In fact, if one removes the larger grains $(>3 \mu \mathrm{m})$, the population of the smaller grains can essentially be described by the same log-normal distribution (see dashed line in Fig. 3a). However, from a volumetric point of view, the large grains can not be neglected; for example one grain of $10 \mu \mathrm{m}$ diameter is of the same volume as 1000 grains of $1 \mu \mathrm{m}$ diameter. Thus, in order to capture a statistically relevant representation for the distribution of larger grains, lower magnification observation is required. Using this approach, the larger ferrite grains were measured showing a log-normal distribution with a median grain size of $4.6 \mu \mathrm{m}$ and a standard deviation of $\sigma=0.56$. Two different regimes of grain size, fine and coarse, can be distinguished from these separate measurements, although there is a small region of overlap for grains in the range of $1-3 \mu \mathrm{m}$.

When considering mechanical behaviour, the volume fraction of individual grain size classes is of primary importance. Using the frequency distribution, i.e. here the log-normal distribution, $f(x)$, volume fraction of grains with size $x, f_{v}$, can be written as:

$f_{V}=\frac{x^{3} f(x)}{\int x^{3} f(x) d x}$

Figure $3 \mathrm{~b}$ shows the volume fraction of grains for the microstructure shown in Figure 2c. For simplicity, the analysis is based on the measured equivalent area diameter rather than the true volumetric diameter. Further, the volume fraction of each class of grain size has been scaled based on the volume fraction of ferrite and martensite in the initial dual phase structure, i.e. $60 \%$ for the coarse grains and $40 \%$ for the fine grains.

The key to understanding how these microstructures develop lies in a consideration of how the ferritemartensite microstructure responds to this processing route. During cold rolling, plastic deformation of martensite occurs. Mazinani and Poole [12] have recently shown that martensite plasticity can be significant in low carbon steels, depending on the carbon concentration and morphology of the martensite phase. This is important because in the absence of plastic deformation of the martensite phase (stage II in
Fig. 1), annealing produces tempered martensite and recrystallization does not occur at short times. For example, Speich and Leslie [17] have reported that recrystallization of martensite in $0.18 \mathrm{wt} \% \mathrm{C}$ steel occurs only after annealing for $96 \mathrm{~h}$ at $600^{\circ} \mathrm{C}$.
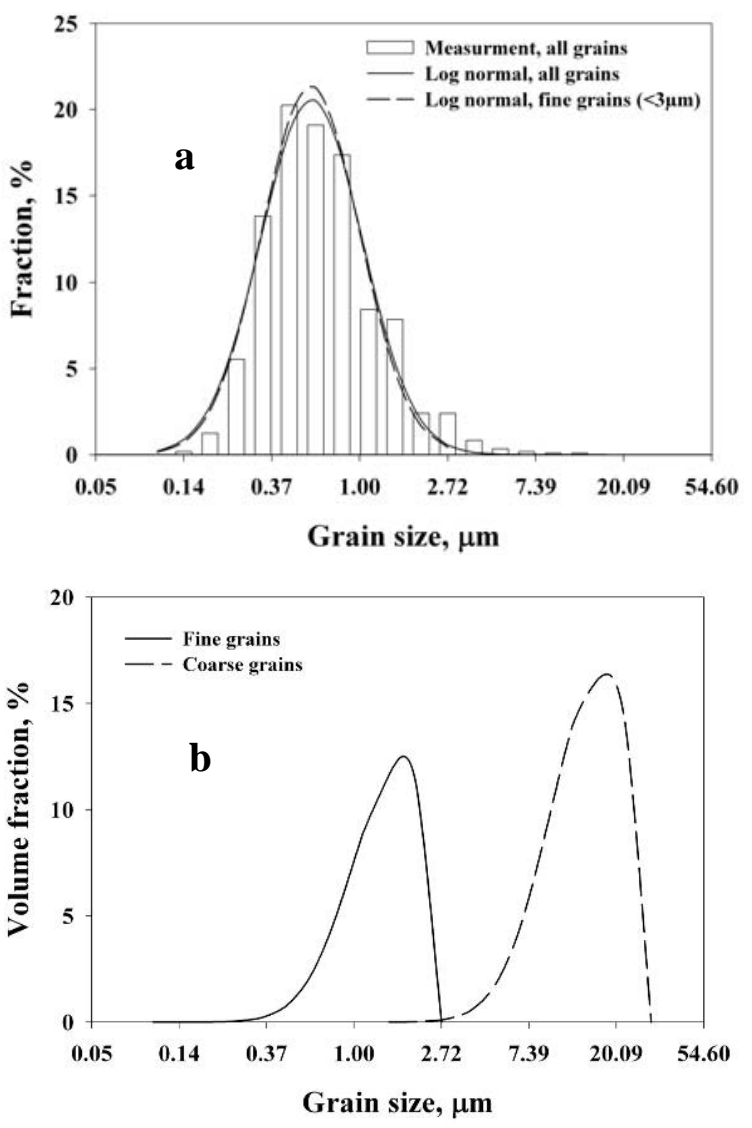

Figure 3. (a) Grain size distribution (b) volume fraction of fine and coarse grain size classes.

In the present case, there is a complex interaction between recrystallization and precipitation that must be controlled to produce the final UFG structure in the martensite regions. It is worth noting that particle pinning is enhanced when interparticle spacing and grain size become comparable, as analyzed in more detail by Bréchet and Militzer [18]. Zhao et al. [12] have also shown that in a steel with 0.45 wt.\%C, comparable with the carbon concentration of martensite in the dual phase structure, ferrite grains with less than $1 \mu \mathrm{m}$ in size will not coarsen even after $3000 \mathrm{~min}$ annealing at $500^{\circ} \mathrm{C}$. On the other hand, the ferrite regions in the microstructure will deform greater than the average during cold rolling (i.e. since the martensite deforms less than average). These regions subsequently recrystallize during annealing. One may speculate because of relatively low number of recrystallization nuclei and the absence of $\mathrm{Fe}_{3} \mathrm{C}$ particles to pin grain boundaries in the ferrite regions, a relatively coarse 
grain structure is produced in these regions compared to the martensite regions.

In order to examine the mechanical response of the bimodal structures, tensile tests were conducted. The ultimate tensile strength (UTS) and uniform elongation of the annealed structure (Fig. $2 \mathrm{c}$ ) is $550 \mathrm{MPa}$ and $14 \%$, respectively (gray line in Fig. 4). In comparison, cold rolling of a fully martensitic structure followed by annealing gives a UTS of $560 \mathrm{MPa}$ and a uniform elongation of $12 \%$, i.e. quite similar results (black line in Fig. 4). However, the material with a bimodal grain distribution shows continuous yielding whereas processing of a fully martensitic steel produced a undesirable Lüders strain of more than $5 \%$. One can speculate that the continuous yielding behavior of bimodal grain structures is similar to observations made for dual phase steels, i.e. the islands of UFG which have a relatively high strength may act in similar manner to martensite islands in the dual phase structures. Thus, the optimum balance of strength and ductility in these composite type structures strongly depends on the morphology, volume fraction and distribution of martensite and ferrite in the dual phase steels and similarly fine and coarse grains in the bimodal structures. An advantage of the present approach is that through controlling the volume fraction, morphology and distribution [19] of ferrite and martensite in the initial dual phase structure it is possible to develop a wide range of various bimodal grain size structures with different fractions of fine and coarse grains etc.

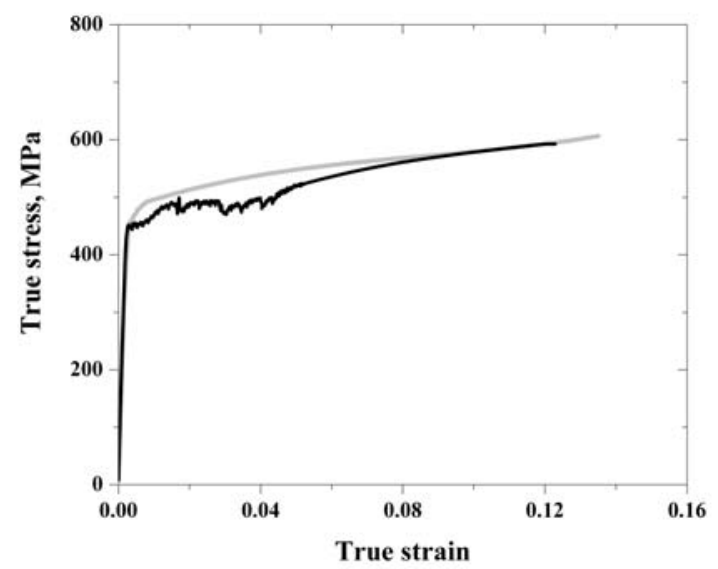

Fig. 4: True stress-true strain curves for bimodal grain size structure (gray line) and a UFG structure (black line).

The present processing route appears to be a very simple method which could be readily applied to the industrial production of sheet. Well established industrial processes, intercritical annealing of hot (or cold) rolled products followed by cold rolling and subsequent batch annealing could be used to produce these microstructures without the need for large strain processes such as equal channel angular extrusion or martensite rolling.

In summary, this study has demonstrated a novel processing route for generating bimodal grain structures in low carbon steels. The processing route is based on rolling and appropriate annealing of ferritemartensite dual phase structures. The concurrent recrystallization of ferrite and martensite combined with carbide precipitation in the martensitic regions are the main mechanisms by which this heterogeneous microstructure can be created. This proposed method may open a new avenue for developing heterogeneous microstructures in order to optimize the balance between strength and uniform elongation in UFG steels.

The authors wish to thank the Natural Sciences and Engineering Research Council of Canada for funding this project through the Strategic Projects Program.

[1] T. Hanamura, F. Yin, K. Nagai, ISIJ Int. 44 (2004) 610.

[2] K. Nagai, J. of Mater. Proc. Tech. 117 (2001) 329.

[3] R. Song 1, D. Ponge, D. Raabe, R. Kaspar, Acta Mater. 53 (2005) 845.

[4] T.C. Lowe, and R. Z. Valiev, JOM. 56 (2004) 64.

[5] N. Tsuji, Y. Saito, H. Utsunomiya, and S. Tanigawa, Scr. Mater. 40 (1999) 795.

[6] N. Tsuji, R. Ueji, Y. Minamino, Y. Saito, Scr. Mater. 46 (2002) 305.

[7] W.C. Leslie, "The physical metallurgy of steels", McGraw-Hill, 1981, p. 21.

[8] R. Song, D. Ponge, D. Raabe, Scr. Mater. 52 (2005) 1075.

[9]Y. Wang, M. Chen, F. Zhou, E. Ma, Nature. 419 (2002) 912.

[10] A. Ohmori, S. Torizuka, K. Nagai, ISIJ Int. 44 (2004) 1063.

[11] Y.M. Wang, E. Ma, Acta Mater. 52 (2004) 1699.

[12] M-C Zhao, T. Nanamura, H. Qui, K. Yang, Metall. Mater. Trans. 37A (2006) 1657.

[13] M. Mazinani, W.J. Poole, Metall. Mater. Trans. 38A (2007) 328

[14] H. Azizi-Alizamini, M. Militzer, W.J. Poole, Advanced Materials Research 15-17 THERMEC 2006 supplement, 750-755 (2007).

[15] H. Azizi-Alizamini, M. Militzer, W. J. Poole: in Advanced Steels, Edited by J.A. Szpunar and H. Li, Metallurgical Society of CIM, Montreal, PQ, (2006) 13.

[16] S.K. Kurtz, F.M.A. Carpay, J. Appl. Phys. 51 (1980) 5725.

[17] G. R. Speich, W.C. Leslie, Metall. Trans. 3 (1972) 1043.

[18] I. Bréchet, M. Militzer, Scr. Mater. 52 (2005) 1299.

[19] J. Huang, M. Militzer, W.J. Poole, Metall. Mater. Trans. 35 (2004) 3363. 